The authors reported no conflicts of interest.

The Journal policy requires editors and reviewers to disclose conflicts of interest and to decline handling or reviewing manuscripts for which they may have a conflict of interest. The editors and reviewers of this article have no conflicts of interest.

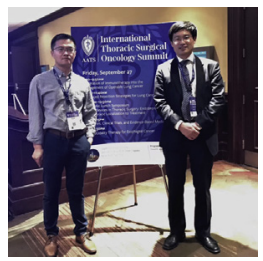

\section{ROBOTIC OR THORACOSCOPIC SEGMENTECTOMY: EACH COMPLEMENTS THE OTHER \\ To the Editor:}

We thank Kim and Bharat for their informative commentary ${ }^{1}$ on our article. ${ }^{2}$ First, results from a single doctor may be influenced by his surgical technique and learning curve, and to minimize the bias, we included data from 3 leading surgeons from 3 large academic institutions, including Hecheng Li from Ruijin Hospital Affiliated to Shanghai Jiao Tong University School of Medicine, Jian Hu from the First Affiliated Hospital of Zhejiang University, and Chun Chen from Fujian Medical University Union Hospital. These institutions are 3 of the few institutions that can perform both robotic and thoracoscopic segmentectomy in China. This study finally included 476 thoracoscopic and 298 robotic segmentectomies with the aim to compare the perioperative outcomes of the 2 surgical approaches using propensity score-matched analysis.

It takes time and experience to master video-assisted thoracoscopic surgery or robotic surgery technology. It is reasonable that the generalization of these techniques to those thoracic surgeons who may lack similar clinical volume is limited. However, with high incidence rate of pulmonary nodules over the years, the number of patients undergoing minimally invasive segmentectomy has increased significantly in some high-volume centers. This study added guidance to the implementation of the technology. The commentary also pointed out that the variability of pathologists may cause differences and bias in nodal station and number. ${ }^{1}$ However, all 3 surgeons dissected lymph nodes and marked out as many as possible during the surgery, so pathologist variability did not influence the results to a great extent.

\footnotetext{
The Editor welcomes submissions for possible publication in the Letters to the Editor section that consist of commentary on an article published in the Journal or other relevant issues. Authors should: • Include no more than 500 words of text, three authors, and five references. • Type with double-spacing. • See http://jtcs.ctsnetjournals.org/ misc/ifora.shtml for detailed submission instructions. • Submit the letter electronically via jtcvs.editorialmanager.com. Letters commenting on an article published in the JTCVS will be considered if they are received within 6 weeks of the time the article was published. Authors of the article being commented on will be given an opportunity of offer a timely response ( 2 weeks) to the letter. Authors of letters will be notified that the letter has been received. Unpublished letters cannot be returned.
}

We did not take the learning curve into account for a number of specific reasons. First, because we included data from 3 different academic institutions, and considering the different number of surgeries performed in these 3 institutions each month and the differences in the learning curve, we included all consecutive data during the study period. Second, at present, the learning curve of robotic and thoracoscopic segmentectomy seems to be similar. In our previous study, ${ }^{3}$ we focused on the learning curve of robotic segmentectomy, and found 40 cases were required to gain technical proficiency and feasible perioperative outcomes. For thoracoscopic segmentectomy, initial reports showed the learning curve to be in the range of 32 to 38 cases. ${ }^{4}$

Current evidence ${ }^{5}$ demonstrates that both robotic and thoracoscopic segmentectomy are safe and feasible for earlystage non-small cell lung cancer treatment, either being the complement of the other. As Kim and Bharat ${ }^{1}$ mentioned, minimally invasive segmentectomy remains a relatively uncommon and technically demanding procedure at several training programs. Moreover, the graduating cardiothoracic surgery residents may not be proficient in the conduct of these procedures. Thus, we should focus on studying the learning curves of these 2 techniques in both experienced and nonleading surgeons as well as studying their safety outcomes. Although our study demonstrated that the robotic approach may lead to a better N1 lymph node dissection, nodal upstaging and long-term results are yet to be confirmed as a potential benefit of robotic surgery in further studies. Thoracic surgeons should choose the appropriate surgical approach after considering the actual situation to provide the better approach for patients receiving minimally invasive segmentectomy.

Yajie Zhang, $M D, P h D$

Xiang Chen, $M D$

Hecheng Li, MD, PhD

Department of Thoracic Surgery

Ruijin Hospital

Shanghai Jiao Tong University School of Medicine

Shanghai, China

Drs Zhang and Chen contributed equally to this letter.

\section{References}

1. Kim SS, Bharat A. Commentary: video-assisted thoracoscopic surgery versus robotic assisted surgery: are we asking the right question? J Thorac Cardiovasc Surg. February 7, 2020 [Epub ahead of print].

2. Zhang Y, Chen C, Hu J, Han Y, Huang M, Xiang J, et al. Early outcomes of robotic versus thoracoscopic segmentectomy for early-stage lung cancer: a multi-institutional propensity score-matched analysis. J Thorac Cardiovasc Surg. January 25, 2020 [Epub ahead of print].

3. Zhang Y, Liu S, Han Y, Xiang J, Cerfolio RJ, Li H. Robotic anatomical segmentectomy: an analysis of the learning curve. Ann Thorac Surg. 2019;107:1515-22.

4. Hamada A, Oizumi H, Kato H, Suzuki J, Nakahashi K, Sho R, et al. Learning curve for port-access thoracoscopic anatomic lung segmentectomy. J Thorac Cardiovasc Surg. 2018;156:1995-2003.

5. Rinieri P, Peillon C, Salaun M, Mahieu J, Bubenheim M, Baste JM. Perioperative outcomes of video- and robot-assisted segmentectomies. Asian Cardiovasc Thorac Ann. 2016;24:145-51.

https://doi.org/10.1016/j.jtcvs.2020.04.110 